\title{
Unfairly Defiled: A Long Term Perspective on Portfolio Insurance as a Strategy for Limiting Portfolio Losses
}

\author{
Jeffrey Ludwig \\ Department of Mathematics, University of California, Irvine, United States of America
}

Email address:

jtludwig@uci.edu

\section{To cite this article:}

Jeffrey Ludwig. Unfairly Defiled: A Long Term Perspective on Portfolio Insurance as a Strategy for Limiting Portfolio Losses. Journal of Investment and Management. Vol. 10, No. 2, 2021, pp. 30-37. doi: 10.11648/j.jim.20211002.12

Received: June 4, 2021; Accepted: June 24, 2021; Published: July 13, 2021

\begin{abstract}
The invention of portfolio insurance as a strategy for limiting portfolio losses was introduced in the early 1980s and gained spectacular popularity throughout the decade, attracting between $\$ 60$ billion to $\$ 90$ billion from institutional money managers. The method provided downside protection against a long equity position by synthetically replicating a long put option using equity futures during an era when exchange-traded equity options were not sufficiently liquid. Unfortunately, the strategy came to a catastrophic end on the "Black Monday" of October 19, 1987, when the president of the New York Stock Exchange shut down the nascent technology used by index arbitrage program trading groups. This caused significant mispricings between futures and cash markets, making the required synthetic put option replication trading impossible. The portfolio insurance strategy was declared a complete failure and never has since regained widespread popularity. Three decades later, modern markets now fully embrace program trading, and the likelihood that program trading would be shut down for any reason ever again seems impossible. This paper examines how portfolio insurance would have performed during the 1991 to 2020 time period, during which 3 major stock market crashes occurred and program trading was never shut down. The paper concludes that portfolio insurance received unjust blame for the 1987 crash and its abandonment since then has been irrational and unfortunate for those seeking long equity exposure with a cost-efficient strategy for limiting portfolio losses.
\end{abstract}

Keywords: Portfolio Insurance, Synthetic Options, Risk Management

\section{Introduction}

An article featured in Fortune magazine in June, 1982, stimulated readers with the opening sentence [1] "It sounds too good to be true: a method for making money in stocks while avoiding their downside risk." What followed in the years to come was a massive inflow of investments from institutional investors across the United States of America, clearly demonstrating the nearly universal appetite for what the creators of the strategy promised in their so-called "protective portfolio management." This underlying financial innovation, also known as portfolio insurance, was introduced in the early 1980s and gained spectacular popularity throughout the decade, attracting between $\$ 60$ billion to $\$ 90$ billion from institutional money managers. The method provided downside protection against a long equity position by synthetically replicating a long put option using equity futures, during an era when exchange-traded equity options were not sufficiently liquid [2]. Remarkably, the strategy continues to be an area of interest in financial innovation in modern finance [3-7].

The strategy worked extremely well in its first 5 years. Then, in an astounding episode in the history of financial markets, demand for the strategy collapsed shortly after the so-called "Black Monday" of October 19, 1987. On this day, in a futile effort to abate a double-digit percentage daily loss in the S\&P 500 equity index, the president of the New York Stock Exchange suddenly and inexplicably shut down the nascent technology used by index arbitrage program trading groups [8]. This caused significant mispricings between futures and cash markets, making the required synthetic put option replication trading required by portfolio insurance nearly impossible. The portfolio insurance strategy was potentially wrongly blamed for the crash on Black Monday, unjustly declared a complete failure, and regrettably has never since regained widespread popularity. Three decades later, modern markets now fully embrace program trading, and the likelihood 
that program trading would be shut down for any reason ever again seems impossible. All of this inspired an investigation into how portfolio insurance would have performed since its abandonment in 1987. This paper examines how portfolio insurance would have performed during the 1991 to 2020 time period, during which 3 major stock market crashes occurred (2000, 2008, and 2020) and program trading was never shut down. The main contribution of the paper will be to provide a rigorous answer the question: Is this method of portfolio management too good to be true?

To begin, a brief review is given on the theoretical stochastic model for the time evolution of a stock's price upon which option pricing theory is based: geometric Brownian motion. This is essential to laying bare the foundation for synthetic replication of options which is at the heart of portfolio insurance [9].

Next, as an aside to stimulate the reader's interest, the merits of options as buy and hold investments is examined, offering a unique perspective since options are more commonly viewed as hedging instruments than investments in research and practice [10]. A theoretical framework is constructed to measure the investment performance of long at-the-money call options and compare that to a long stock position, under the quixotic assumption that the stock price follows the geometric Brownian motion model. Within this framework it is straightforward to evaluate whether or not it is better to buy and hold at-the-money call options, or buy and hold the underlying stock.

Finally, the results of the main experimental simulation of this paper are elucidated in measuring how the portfolio insurance strategy would have performed during the 1991 to 2020 time period. The paper concludes with an impartial discussion of the merits and limitations of portfolio insurance.

\section{Black-Scholes Option Pricing Formula}

In this section the derivation of the famous Black-Scholes formula for the price of a European call option is given, first published by Fischer Black and Myron Scholes in 1973 [11]. The Black-Scholes option pricing theory assumes that the stock price evolves according to geometric Brownian motion [12-15]. This model assumes a stochastic differential equation of the form

$$
\frac{d S}{S}=\mu d t+\sigma d w
$$

A description of the model and its parameters is as follows:

1. During a small time increment $d t, S$ changes to $S+d S$

2. The return $\frac{d S}{S}$ has predictable and random components

3. The predictable component is $\mu d t$, where $\mu$ is the average annual growth rate of the stock price

4. The random component is $\sigma d w$, where $\sigma$ is a measure of the standard deviation of continuously compounded annual returns, and $d w$ is a random number drawn from a normal distribution with mean zero and variance equal to $d t$

5. This random walk in stock price is known as geometric Brownian motion, named after the Scottish botanist Robert Brown

6. The process $w$ in $d w$ is denoted a "Wiener Process," after Nobert Wiener from MIT

Ito's Lemma is needed to derive the explicit formula for $S(t)$, the stochastic process associated with geometric Brownian motion. For our purposes, for a function $V=$ $V(S, t)$, Ito's Lemma [16] may be written as

$$
d V=\sigma S \frac{\partial V}{\partial S} d w+\left(\mu S \frac{\partial V}{\partial S}+\frac{\partial V}{\partial t}+\left(\frac{1}{2}\right) \sigma^{2} S^{2} \frac{\partial^{2} V}{\partial S^{2}}\right) d t
$$

With $V=\ln S$ and $\frac{d S}{S}=\mu d t+\sigma d w$, it follows that

$$
\frac{\partial V}{\partial S}=\frac{1}{S} \quad \frac{\partial^{2} V}{\partial S^{2}}=\frac{-1}{S^{2}} \quad \frac{\partial V}{\partial t}=0
$$

such that

$$
d V=\left(\mu-\frac{1}{2} \sigma^{2}\right) d t+\sigma d w
$$

Integrating, an expression for the terminal stock price $S(T)$ is given by

$$
S(T)=S(t) \exp \left\{\left(\mu-\frac{1}{2} \sigma^{2}\right)(T-t)+\sigma v\right\}
$$

In a risk neutral world [10], we may assume $\mu=r$ and we arrive at

$$
S(T)=S(t) \exp \left\{\left(r-\frac{1}{2} \sigma^{2}\right)(T-t)+\sigma v\right\}
$$

In order to derive the Black-Scholes European call option price formula, the expected value of a nonlinear function of a normal random variable, $v$, taken with respect to its probability density function, is computed. This is true since the European call option value is equal to its discounted expected payoff at expiration:

$$
C_{X}(t)=e^{-r(T-t)} E\{\max [0, S(T)-X] \mid S(t)\}
$$

which may be shown [11] to lead to the famous Black-Scholes European call option formula

$$
\begin{gathered}
C_{X}(t)=S(t) N\left(d_{1}\right)-e^{-r(T-t)} \mathrm{X} N\left(d_{2}\right) \\
d_{1}=\frac{\ln \left(\frac{S(t)}{X}\right)+\left(r+\frac{1}{2} \sigma^{2}\right)(T-t)}{\sigma \sqrt{(T-t)}} \\
d_{2}=d_{1}-\sigma \sqrt{(T-t)} \\
N(x)=\frac{1}{\sqrt{2 \pi}} \int_{-\infty}^{x} e^{-\frac{1}{2} z^{2}} d z
\end{gathered}
$$

A summary of the variables in the formula for $C_{X}(t)$ is as follows 
$C_{X}(t)=$ call option price
$S(t)=$ current stock price
$X=$ strike price of the option
$r=$ risk-free interest rate
$\sigma=$ standard deviation of the continuously compounded
annual stock returns

$T=$ maturity date

$(T-t)=$ time to option maturity (in years)

$N(x)=$ normal cumulative distribution function

It is important to note that it is well-known and universally surprising that the Black-Scholes European call option formula does not depend on the average annual growth rate of the stock price $\mu$. Of course the expected value of the stock price at expiration does depend on $\mu$, as does the expected return of the call option as a buy and hold investment. This conundrum motivates the topic of the next section.

\section{Options as a Buy and Hold Investments}

In this section, as a precursor to the historical evaluation of portfolio insurance, an investment of long call options is examined as a buy and hold investment. The theoretical investment performance ${ }^{1}$ of long at-the-money one-year call options is compared to that of long stock, under the assumption that the stock price follows the geometric Brownian motion model. For long term investors, is it better to buy and hold atthe-money 1-year call options, or buy and hold the underlying stock? A constant annual volatility $\sigma=0.30$ is assumed in this analysis.

It will turn out that the answer depends on the assumption for the expected growth rate $\mu$ in this entirely theoretical framework.

\section{Monte Carlo Simulations}

Assuming the stock price follows geometric Brownian motion, the evolution of the stock price over a small increment in time $\Delta t$ may be approximated using the Monte Carlo method as

$$
S\left(t_{j+1}\right)=S\left(t_{j}\right) e^{\left[\left(r-\frac{1}{2} \sigma^{2}\right)(\Delta t)+\sigma \sqrt{(\Delta t)} \epsilon_{j+1}\right]}
$$

where $\epsilon_{j+1} \sim N(0,1)$, i.e., $\epsilon_{j+1}$ is a normally distributed random variable with zero mean and unit variance.

The results using 10,000 Monte Carlo simulations are summarized in Table 1 and illustrated in Figures 1 and 2. With Monte Carlo simulations assuming a positive expected growth rate $\mu>0$, the results demonstrate unambiguously
1. The long stock strategy has a higher Sharpe ratio, and

2. The long at-the-money call option has a higher expected return

Interestingly, these results are reversed when the assumed expected growth rate is negative $(\mu<0)$, as can be seen in Figures 1 and 2 . These theoretical conclusions may provide insight into equity derivatives portfolio managers' daunting task of securities selection.

Table 1. Summary of Superior Investment Strategy.

\begin{tabular}{lll}
\hline Performance Metric & $\mu \geq \mathbf{0}$ & $\mu<\mathbf{0}$ \\
\hline Mean Return & Long Call Option & Long Stock \\
Sharpe Ratio & Long Stock & Long Call Option \\
\hline
\end{tabular}

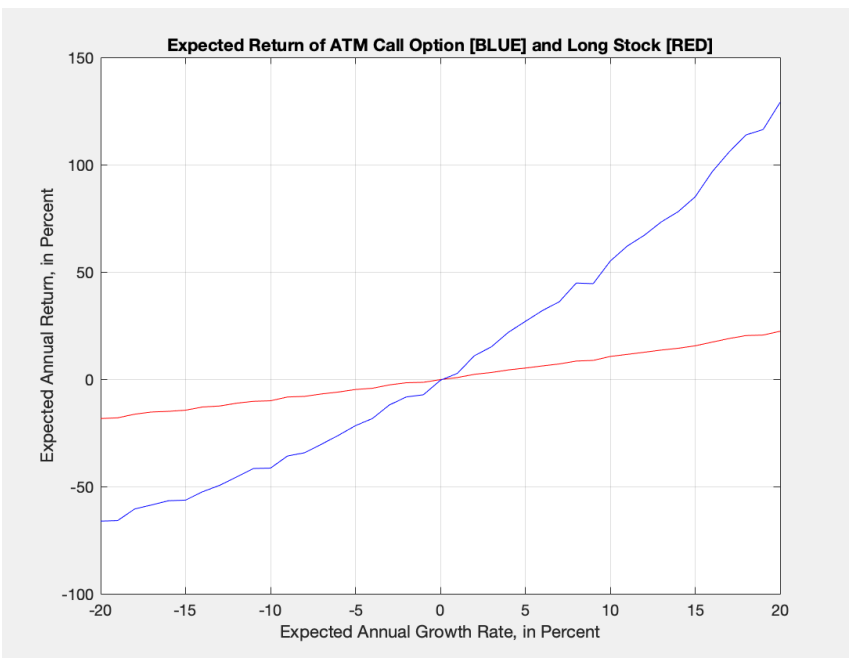

Figure 1. Mean Return vs. Value of Expected Growth Rate $\mu$.

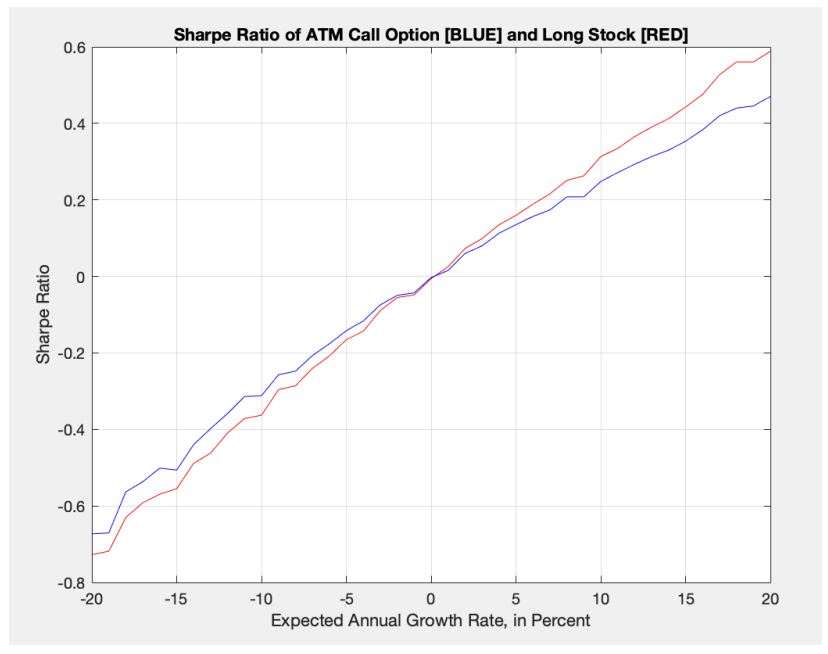

Figure 2. Sharpe Ratio vs. Value of Expected Growth Rate $\mu$.

\footnotetext{
${ }^{1}$ The metric we use for theoretical investment performance is the Sharpe ratio, equal to the mean excess return divided by the standard deviation of excess return, where the excess return is measured relative to the risk free rate
} 


\section{Synthetic Replication of Long Call Option}

The original paper on the Black-Scholes options pricing theory relied on a no-arbitrage argument to derive a stochastic partial differential equation that must hold for all derivative securities: "if options are correctly priced in the market, it should not be possible to make sure profits by creating portfolios of long and short positions in options and their underlying stocks" [11]. This reasoning led to the celebrated Black-Scholes equation

$$
\frac{\partial V}{\partial t}+\frac{1}{2} \sigma^{2} S^{2} \frac{\partial^{2} V}{\partial S^{2}}+r S \frac{\partial V}{\partial S}-r V=0
$$

Essential to this derivation is the fact that theoretically an option may be synthetically replicated [2] with a position in the underlying stock in addition to borrowing or lending at the risk free rate $r$. A synthetic call option $C_{S}$ is created using a replication strategy [9] where a position in the stock itself of $\Delta_{C}$ units is maintained via daily dynamic delta hedging, where $\Delta_{C}$ is easily computed as

$$
\Delta_{C}=N\left(d_{1}\right)
$$

where, as before,

$$
N(x)=\frac{1}{\sqrt{2 \pi}} \int_{-\infty}^{x} e^{-\frac{1}{2} z^{2}} d z
$$

Now consider two portfolios

1. Owning a stock along with the right to sell it

$$
S+P
$$

2. Having the right to buy the stock together with enough money at expiration to exercise that right

$$
C+X e^{-r(T-t)},
$$

where, as before, $X$ is the strike price of the options. Clearly at expiration, by definition these portfolios have identical payoffs, assuming the put option and the call option have the same strike price $X$ and expiration date $T$. With identical payoffs at expiration, a no-arbitrage argument asserts that the portfolio values at any time before expiration must also be the same. This leads to the put-call parity equation:

$$
S+P=C+X e^{-r(T-t)}
$$

An insured portfolio $S+P$ is thus identical to $C+$ $X e^{-r(T-t)}$. This relationship is fundamental to the portfolio insurance simulation: the performance of $S+P$ will be compared to that of $C+X e^{-r(T-t)}$, using a synthetic call option $C_{S}=\Delta_{C}$, plus appropriate borrowing/lending at the risk free rate $r$, instead of the exchange-traded call option $C$. The value of $\Delta_{C}$ changes as the underlying stock price changes, so daily delta hedging must be used to maintain the highest precision synthetic call that is possible. The volatility $\sigma$ and risk-free rate $r$ are assumed to be constant throughout the year and updated annually on the first day of the year.

\section{Portfolio Insurance Simulation}

In this simulation the 30 -year investment performance of two portfolios is compared:

1. Long the S\&P 500 equity index plus long an at-themoney exchange-traded one-year put option, with the put option being rolled on the first trading day of each year. This portfolio is denoted $S+P$

2. Long a synthetic at-the-money one-year call option plus cash invested at the risk free rate $r$. This portfolio is denoted $P I$.

The volatility $\sigma$ and risk free rate $r$ are updated on the first trading day of each calendar year, and assumed to be constant throughout the year. Portfolio (2) is the portfolio corresponding to portfolio insurance, and can be viewed as a synthetic form of $S+P$ due to put-call parity. The amount of cash invested is such that the total cash outlays are the same for portfolios (1) and (2). The amount $\Delta_{C}=N\left(d_{1}\right)$ varies with the daily S\&P 500 equity index price, so daily delta hedging is used to maintain the highest precision synthetic call that is possible.

\section{Simulation Results}

First, the historical implied volatility using the VIX Index is computed. These values on the first trading day of each calendar year are shown in Figure 3. Figure 4 shows the corresponding Black-Scholes price of an at-the-money (ATM) exchange-traded put option, expressed as a percentage of the S\&P 500 index price (SPX). Figures 5 and 6 show the strike price of the 1-year ATM put option and risk-free annual interest rate, as measured by 3-month US treasury bills, both important variables in the portfolio insurance simulation.

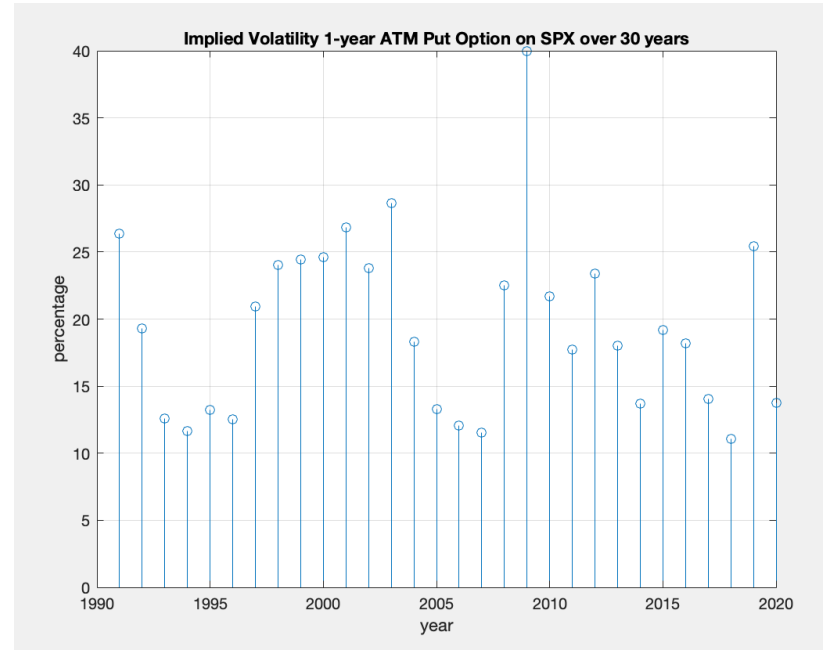

Figure 3. Implied Volatility of 1-year ATM Put Option on SPX over 30 Years. 


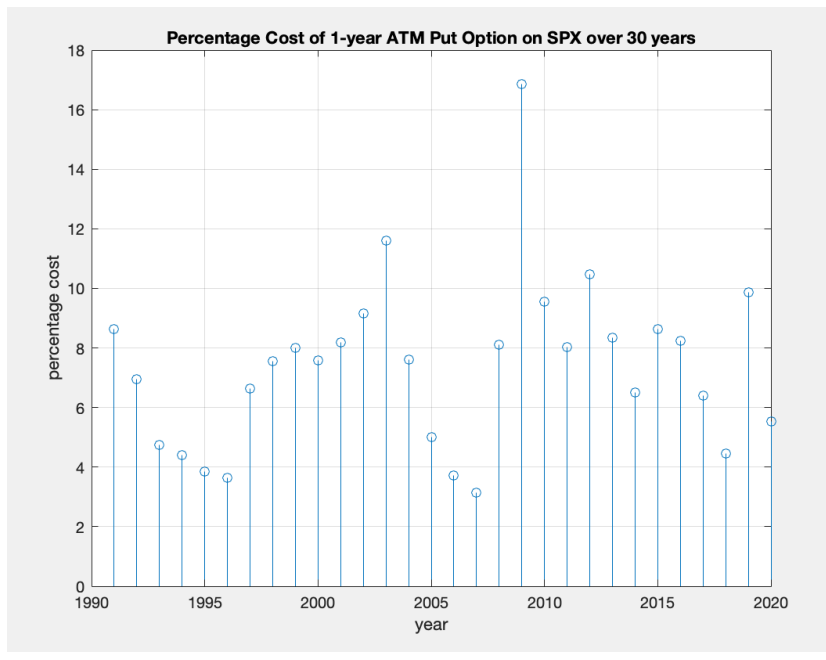

Figure 4. Percentage Cost of 1-year ATM Put Option on SPX over 30 Years.

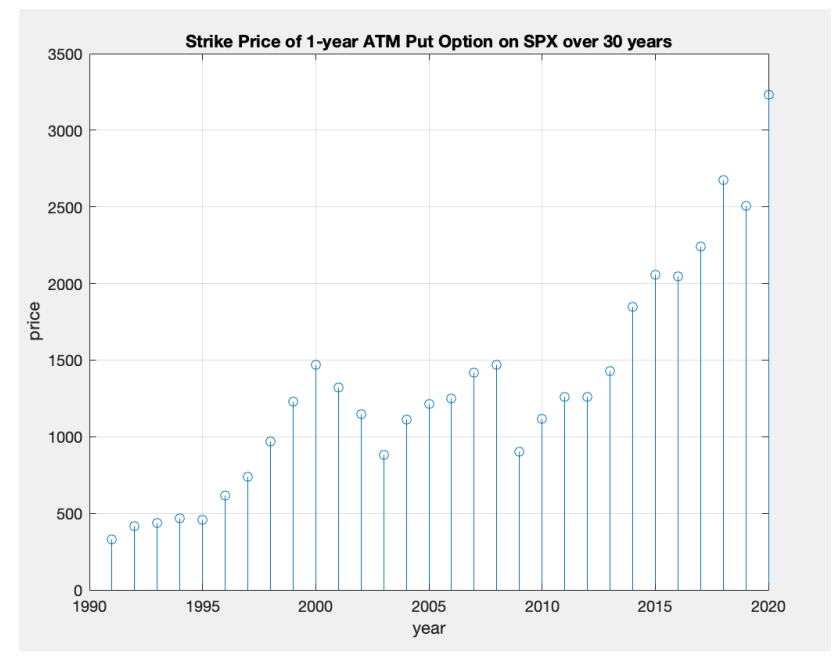

Figure 5. Strike Price of 1-year ATM Put Option on SPX Over 30 years.

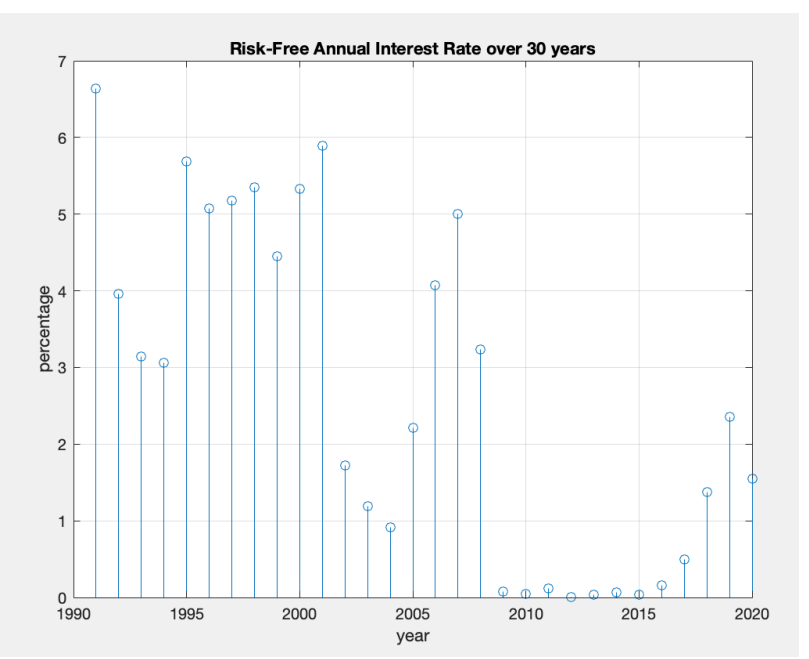

Figure 6. 3-month U.S. Treasury Annual Interest Rate Over 30 years.

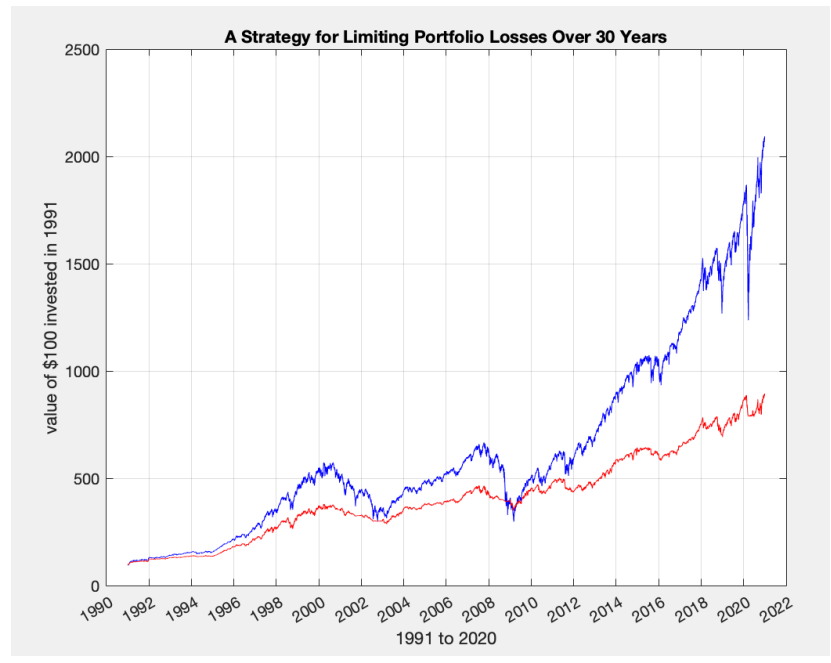

Figure 7. $S \& P 500$ Index (BLUE) and Portfolio Insurance (RED).

Figure 7 shows the main result of the portfolio insurance simulation. Dividend payments on the SPX are assumed to be distributed evenly across all the trading days of each year. Starting with $\$ 100$ in 1991, the cumulative growth in wealth is shown for the SPX in blue and for portfolio insurance in red. Clearly the portfolio insurance limits losses, as promised, while capturing a good amount of the upside gains. A stunning result is that the annualized Sharpe ratio of the portfolio insurance is 0.63 , while the Sharpe ratio of the SPX is 0.55 over this time period. The return per unit risk of the portfolio insurance is higher than that of the SPX. Interestingly, the monthly returns of the SPX are higher than the monthly returns of the portfolio insurance strategy in 243 out of the 360 months in the simulation, but the Sharpe ratio is lower. This illustrates the powerful loss-limiting risk management capability of portfolio insurance: the large drawdowns in the SPX are attenuated in exchange for modest underperformance in the positive months.

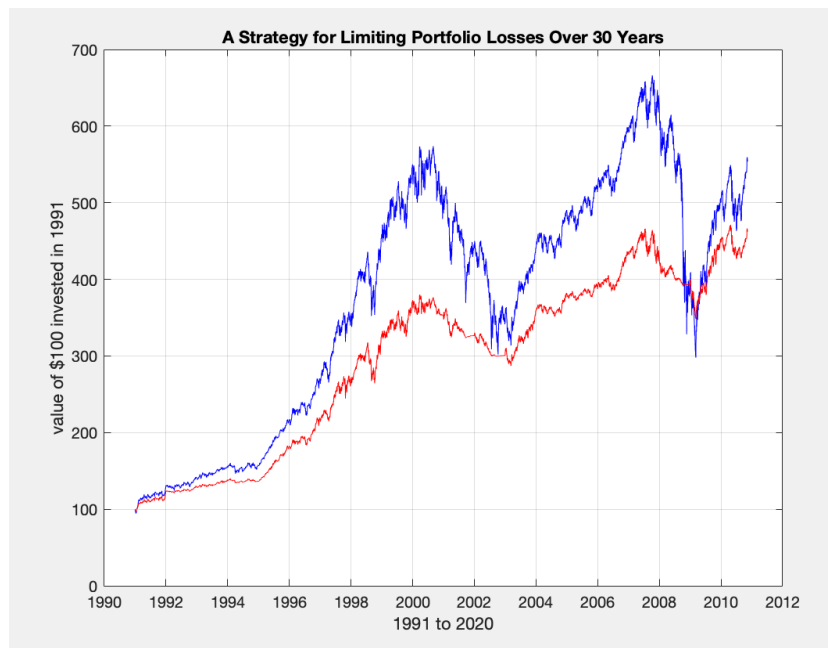

Figure 8. S\&P 500 Index (BLUE) and Portfolio Insurance (RED).

Figure 8 illuminates the first twenty years of the simulation, 
1991 to 2010 , during which the portfolio insurance strategy achieves almost exactly the same growth in wealth as the SPX while encountering significantly less volatility and peak-totrough drawdowns along the way. This time period was an excellent one to have been invested in the portfolio insurance strategy.

\section{Discussion}

One main driver for the original use of synthetic options for portfolio insurance was that exchange-traded options were not available at the time. That is clearly no longer the case. Impetus for this research was derived from a widespread curiosity: the cost of ATM exchange-traded put options is known in advance. But what is the equivalent cost of a synthetically replicated put option? Is it better to use a synthetic or exchange-traded put option if an investor seeks downside protection? The effective annual cost of the synthetic put options is computed and compared to the annual cost of the exchange-traded put options for comparison in Table 3 in the Appendix. In sum, the synthetically replicated put options are cheaper than exchange-traded put options in 21 out of 30 years. This is a reflection of the casual observation that historically, most of the time, implied volatilities are higher than realized volatilities. The average annual synthetic put option cost is $6.5 \%$ while the average annual exchangetraded put option cost is $7.4 \%$.

Furthermore, Table 3 shows the average of annual returns, standard deviation of annual returns, and Sharpe ratio for three strategies considered in this simulation: S\&P $500+$ synthetic ATM put option, S\&P 500, S\&P $500+$ exchange-traded ATM put option $\mathrm{P}$

Table 2. Performance Comparison of Portfolio Management Strategies.

\begin{tabular}{llll}
\hline Strategy & Mean & Standard Deviation & Sharpe Ratio \\
\hline S\&P 500 + synthetic P & 6.03 & 9.52 & 0.63 \\
S\&P 500 & 10.09 & 18.31 & 0.55 \\
S\&P 500 + P & 4.75 & 11.47 & 0.41 \\
\hline
\end{tabular}

Our portfolio insurance simulation demonstrates that the Sharpe ratio of the S\&P $500+$ synthetic put option strategy (portfolio insurance) is higher than that of the S\&P 500, while the S\&P $500+$ exchange-traded put option has a lower Sharpe ratio than that of the S\&P 500 . The portfolio insurance strategy shows outstanding resilience during market crashes in 2000-2002, 2008, and 2020, with only one hiccup during March 2020. In this volatile month, the market experienced 2 of the top 10 biggest down days in history as well as 2 of the top 10 biggest up days in history. This is an uncanny and brutal example of exactly what the originators of portfolio insurance warned against in a footnote of their original paper [2]: Remember that the analogy to insurance breaks down under a sudden catastrophic loss that does not leave sufficient time to adjust the replicating portfolio. This is exactly what happened during the onset of the COVID-19 pandemic in March 2020, during which the S\&P 500 encountered daily losses of $-11.98 \%$ on March 16 and $-9.51 \%$ on March 12 , along with daily gains of $+9.38 \%$ on March 24 and $+9.29 \%$ on March 13. During this month the world faced despair and uncertainty, and the extreme market volatility caused the portfolio insurance to struggle. Aside from March 2020, in all of the other 359 out of 360 months during the past 30 years portfolio insurance worked like a charm.

One last thing to note is that the value of exchange-traded put options usually soars in a market crash, delivering to the long put holder a double-whammy of positive returns: the spike in volatility plus the spike in intrinsic value of the put option both boost the option value as the stock price falls. This rare positive effect is hard to predict and capture, and is thus not a robust and reliable portfolio management methodology.

\section{Transaction Costs}

Transaction costs are extremely important in simulations and real portfolio management, and conservative assumptions should always be made. Transaction costs spoil many mathematically elegant theories and innovations, as summarized in the following quote

Transactions costs invalidate the Black-Scholes arbitrage argument for option pricing, since continuous revision implies infinite trading. Discrete revision using Black-Scholes deltas generates errors which are correlated with the market, and do not approach zero with more frequent revision when transactions costs are included. [9]

The negative effect of market impact combined with trading fees is what many quantitative traders call slippage. Portfolio insurance, or any strategy for that matter that requires rebalancing involving selling as prices fall and buying as prices go up must carefully take slippage into account when framing performance expectations. As the size of the managed positions grows relative to the total market capitalization, slippage becomes critically important.

In this simulation the average annual transaction cost is 0.04783 per basis point slippage vs. arrival price. This means that if the average slippage in trading were 5 basis points, then the total transaction costs on average would lower the annual returns shown in Table 2 by $5 * 0.04783=0.24 \%$. This is a modest yet non-negligible amount.

For a more comprehensive and generic analysis of the effect of transaction costs on investment performance, the Breakeven Slippage Ratio (BSR) is introduced as the ratio of annual average profit to annual average trading volume required to achieve that profit. Then if a strategy realizes an actual average

\footnotetext{
${ }^{2}$ The zero-slippage Sharpe ratio $S_{Z}$ is the Sharpe ratio obtained in simulations assuming zero transaction costs
} 
slippage of $\bar{s}$, then it can be easily shown that the relationship between realized Sharpe ratio $S_{R}$ and zero-slippage Sharpe ratio $S_{Z}$ is given as ${ }^{2}$

$$
S_{R}=\frac{(\mathrm{BSR}-\bar{s})}{\mathrm{BSR}} S_{Z}
$$

This metric is as useful as Sharpe ratio in terms of assessing the sensitivity of a portfolio management strategy to assumptions about transactions costs. Clearly as the BSR increases, the effect of $\bar{s}$ on $S_{R}$ diminishes. In sum, high BSRs may be as important as high zero-slippage Sharpe ratios in simulations. The BSR for the portfolio insurance strategy described in this paper is equal to 135 basis points.

\section{Conclusion}

The first contribution of this paper was to compare in a purely theoretical framework the relative investment performance of long stock positions compared to long atthe-money call options. It was shown clearly that the long stock strategy has a higher Sharpe ratio while the long at-themoney call option has a higher expected return, assuming the constant growth rate of the stock is positive. These results are reversed when the assumed expected growth rate is negative. These theoretical conclusions may provide insight into equity derivatives portfolio managers' daunting task of securities selection.

The second contribution of this paper was to perform a long term historical simulation of portfolio insurance. Portfolio insurance as a strategy for limiting portfolio losses was introduced in the early 1980s and gained spectacular popularity and success throughout its first few years. After the crash of October 19, 1987, its use was abandoned and it never regained popularity as the consensus was that the strategy was somehow responsible for the crash. This paper has shown through simulation that portfolio insurance would have performed exactly as intended during the 1991 to 2020 time period, during which 3 major stock market crashes occurred.

In fact the synthetically replicated put options associated with portfolio insurance are shown in this paper to be cheaper than exchange-traded put options in 21 out of 30 years in the simulation. This is a reflection of the casual observation that historically, most of the time, implied volatilities are higher than realized volatilities. All this may suggest that portfolio insurance received unjust blame for the 1987 crash and its abandonment since then has been irrational and unfortunate for those seeking long equity exposure with a cost-efficient strategy for limiting portfolio losses. Perhaps the rebirth of a left-for-dead brilliant innovation in finance, portfolio insurance, is on the horizon.

\section{Acknowledgements}

The author is profoundly grateful for insightful suggestions and feedback from Hayne Leland and Ed Thorp, who kindly took the time to read this paper.

\section{Appendix}

Table 3. Comparison of Exchange-Traded and Synthetic Put Options.

\begin{tabular}{|c|c|c|c|c|c|}
\hline Year & $\mathbf{P}$ & $\mathbf{S}$ & $\mathbf{S}+\mathbf{P}$ & PI & Synthetic $\mathrm{F}$ \\
\hline 1991 & 8.63 & 33.90 & 25.27 & 25.30 & 8.60 \\
\hline 1992 & 6.96 & 7.50 & 0.54 & 4.30 & 3.20 \\
\hline 1993 & 4.74 & 9.90 & 5.16 & 6.20 & 3.70 \\
\hline 1994 & 4.40 & 1.50 & -2.90 & -0.30 & 0.30 \\
\hline 1995 & 3.86 & 38.70 & 34.84 & 33.50 & 5.20 \\
\hline 1996 & 3.64 & 21.40 & 17.76 & 17.60 & 3.80 \\
\hline 1997 & 6.64 & 34.70 & 28.06 & 26.90 & 7.80 \\
\hline 1998 & 7.56 & 27.90 & 20.34 & 19.60 & 8.30 \\
\hline 1999 & 8.01 & 20.00 & 11.99 & 14.00 & 6.00 \\
\hline 2000 & 7.59 & -10.80 & -7.59 & -6.20 & 6.20 \\
\hline 2001 & 8.20 & -8.80 & -8.20 & -5.70 & 5.70 \\
\hline 2002 & 9.17 & -20.00 & -9.17 & -6.60 & 6.60 \\
\hline 2003 & 11.59 & 24.20 & 12.61 & 17.30 & 6.90 \\
\hline 2004 & 7.62 & 10.30 & 2.68 & 6.00 & 4.30 \\
\hline 2005 & 5.01 & 7.50 & 2.49 & 2.80 & 4.70 \\
\hline 2006 & 3.73 & 13.80 & 10.07 & 10.90 & 2.90 \\
\hline 2007 & 3.13 & 4.10 & 0.97 & -1.80 & 5.90 \\
\hline 2008 & 8.11 & -34.00 & -8.11 & -6.10 & 6.10 \\
\hline 2009 & 16.87 & 24.50 & 7.63 & 13.00 & 11.50 \\
\hline 2010 & 9.56 & 14.50 & 4.94 & 6.60 & 7.90 \\
\hline 2011 & 8.02 & 2.50 & -5.52 & -8.60 & 11.10 \\
\hline 2012 & 10.47 & 17.10 & 6.63 & 9.20 & 7.90 \\
\hline 2013 & 8.35 & 28.00 & 19.65 & 21.90 & 6.10 \\
\hline 2014 & 6.49 & 14.70 & 8.21 & 8.00 & 6.70 \\
\hline 2015 & 8.64 & -0.10 & -8.64 & -4.60 & 4.60 \\
\hline 2016 & 8.24 & 14.70 & 6.46 & 7.10 & 7.60 \\
\hline 2017 & 6.39 & 21.80 & 15.41 & 16.40 & 5.40 \\
\hline 2018 & 4.47 & -5.40 & -4.47 & -6.70 & 6.70 \\
\hline 2019 & 9.86 & 32.40 & 22.54 & 23.60 & 8.80 \\
\hline 2020 & 5.53 & 16.70 & 11.17 & 3.00 & 13.70 \\
\hline
\end{tabular}

\section{References}

[1] Greenbaum, M. A strategy for limiting portfolio losses. Part Pub. Date: Fortune, June 14, 1982, Vol. 105, p. 209 (2).

[2] Rubinstein, M. \& Leland, H. E. Replicating Options With Positions in Stock and Cash Article in Financial Analysts Journal, July 1981. https://doi.org/10.2469/faj.v37.n4.63

[3] Katsikis, Vasilios N. and Mourtas, Spyridon D. Portfolio Insurance and Intelligent Algorithms, pp. 305-323, in Computational Management: Applications of Computational Intelligence in Business Management. Springer International Publishing, 2021. https://doi.org/10.1007/978-3-030-72929-5_14 
[4] Medvedeva, MA, Katsikis, VN, Mourtas, SD, Simos, TE. Randomized time-varying knapsack problems via binary beetle antennae search algorithm: Emphasis on applications in portfolio insurance. Math Meth Appl Sci. 2021; 44: 2002-2012. https://doi.org/10.1002/mma.6904

[5] Katsikis, Vasilios N. and Mourtas, Spyridon D. Binary Beetle Antennae Search Algorithm for Tangency Portfolio Diversification. Journal of Modeling and Optimization. Vol 13 No 1, 2021. https://doi.org/10.32732/jmo.2021.13.1.44

[6] Ruehl, Thorsten. Quant Models for Robo-Advisors. Robo-Advisory: Investing in the Digital Age, pp 71-92. 2021. https://doi.org/10.1007/978-3-030-40818-3_5

[7] Alan, Nazli Sila and Mahoney, Timothy and Schwartz, Robert A. Invited Editorial: Combatting Turbulence in the Equity Market-Get the Listed Companies on Board in Equity Trading Round-Up: Proposals for Strengthening the Markets. Springer International Publishing, 2021. https://doi.org/10.1007/978-3-030-51015-2_10

[8] Henriques, D. B. A First-Class Catastrophe: The Road to Black Monday, the Worst Day in Wall Street History. Henry Holt and Co.; 1st Edition (September 19, 2017). https://us.macmillan.com/books/9781627791649

[9] Leland, H. Option Pricing and Replication With Transaction Costs. January 1985. The Journal of Finance
40 (5): 1283-1301 https://doi.org/10.1111/j.15406261.1985.tb02383.x

[10] Hull, J. C. Options, Futures and Other Derivatives, fourth edition, 2000. Upper Saddle River, Prentice Hall, New Jersey.

[11] Black, F., \& Scholes, M. The Pricing of Options and Corporate Liabilities. The Journal of Political Economy, 81 (3) (May - Jun., 1973), pp. 637-654. http://dx.doi.org/10.1086/260062

[12] Cox, J. C, Ross, S. A., and Rubinstein, M. Option pricing: A simplified approach. Journal of Financial Economics, 7 (3), September 1979. pp. 229-63. https://doi.org/10.1016/0304-405X(79)90015-1

[13] Merton, R. C. Theory of Rational Option Pricing. The Bell Journal of Economics and Management Science, 4 (1), pp. 141 to 183 . https://doi.org/10.2307/3003143

[14] Black, F. How we came up with the option formula. Journal of Portfolio Management, 1989, 15 (2), pp. 4-8.

[15] Bernstein, P. L. 1992. Capital Ideas, The Improbable Origins of Modern Wall Street, New York, London, Toronto, Sydney, Tokyo, Singapore. The Free Press.

[16] Kiyosi Ito. Stochastic Integral. Proceedings of The Imperial Academy, October 12, 1944. Tokyo 20 (8), pp. 519 to 524. https:/doi.org/10.3792/pia/1195572786 